\title{
Revisitando Morin: os novos desafios para os educadores
}

Lucilene Cury* Graduada na Área de Educação pela Universidade Estadual Paulista Júlio de Mesquita Filho. Desenvolveu os estudos de Pós-Graduação na Área de Comunicação: mestrado e doutorado em Ciências da Comunicação pela Universidade de São Paulo, com pesquisas sobre a TV e a Criança; o Rádio e a Literatura Latino-Americana para Crianças Brasileiras. Realizou estudos de Pós-Doutorado em Paris, na Sorbonne, voltados à Televisão. Atualmente é docente da Universidade de São Paulo. Tem experiência na área de Comunicação, com ênfase em Interdisciplinaridade, nas Diversas Áreas da Pesquisa da Comunicaşão, atuando principalmente nos seguintes temas: globalização, cultura, educaşão, comunicação e internet. Coordena o Grupo de Pesquisa - Cibernética Pedagógica: Laboratório de Linguagens Digitais -, certificado pelo CNPq, onde estudantes e pesquisadores desenvolvem projetos de pesquisa relacionados ao mundo virtual e à inclusão digital/social, tais como: "Atalhos para a Inclusão Digital"; "Educação no Ciberespaço" e "O Mundo Virtual é para Todos?". Link para o Grupo de Pesquisa Cibernética Pedagógica - Laboratório de Linguagens Digitais: Cibernética Pedagógica - Laboratório de Linguagens Digitais - USP.

E-mail: lucilene@usp.br

Resumo: Por meio da releitura das obras de maior destaque do filósofo, antropólogo e sociólogo francês Edgar Morin, o texto propõe uma reflexão sobre os atuais desafios educacionais impostos pelas novas tecnologias da informação e comunicação (TICs).

Palavras-chave: Educação, pensamento complexo, comunicação, ética, TICs.
Abstract: Through the rereading of the most outstanding works of the French philosopher, anthropologist and sociologist Edgar Morin, this chapter proposes a reflection on the current educational challenges posed by new information and communication technologies (ICTs).

Keywords: Education, complex thought, communication, ethics, ICTs.

As resistências geradas pelas propostas de reforma nas estruturas sociais, a partir das instituições de ensino, encontram sempre oposição por parte dos conservadores que imputam ao sistema de ensino a linha de frente de perpetuação de suas ideologias. Para melhor compreensão desse pensamento inicial podemos fazer menção ao Emílio, de Jean Jacques Rousseau, que escrito em 1762 foi queimado em Paris e em Genebra, sob a acusação de conter fragmentos de contestação à ordem católica. Contraditoriamente a esse fato, foi um dos livros mais lidos na Europa do século XVIII e serviu como inspiração para o novo sistema educativo nacional instaurado pela Revolução Francesa ${ }^{1}$, que foi modelo, inclusive, para o nosso sistema educacional.

Recebido: 26/10/2011

Aprovado: 06/12/2011

* Artigo elaborado na disciplina Tecnologias Digitais em Espaços Educativos (CCA5914), do Programa de Pós-Graduação em Ciências da Comunicação da Escola de Comunicações e Artes da Universidade de São Paulo (ECA / USP), durante $\circ 2^{\circ}$ semestre de 2011, sob responsabilidade da Profa. Dra. Lucilene Cury, com os seguintes alunos, em nível de Mestrado e Doutorado: Amanda Bastos Mareschi Aggio; Ana L. G. Ispada; Andressa C. L. Mouta; Antonio H. Junqueira; Bruno M. Franques; Carlos A. T. Junior; Carmen L. M. E. Gattás; Cláudia Rodriguez Dominguez; Débora M. A. Estrela; Débora Rodrigues Vaz; Denise M. de Almeida; Douglas Pigozzi; Helena Corazza; José Luiz dos Santos; José V. M. P. e Silva; Lourival da Cruz Galvão Júnior; Lucilene S. S. Fonseca; Luiz Carlos Paloschi; Margarete de Moraes; Nicolle C. Sant'Ana e Roberto Padula.

1. Jean Bloch traça a recepção da obra na França, particularmente entre os revolucionários, em sua obra Rousseanismo y educación en la Francia del siglo XVIII. Oxford: Voltaire Foundation, 1995. 
comunicação \& educação • Ano XVII • número 1 • jan/jun 2012

Nessa linha de pensamento, Edgar Morin relata no prefácio de seu livro A cabeça bem-feita ${ }^{2}$ que, por sugestão de Jack Lang, então ministro da França, iniciara "algumas anotações para um Emílio contemporâneo". Essa alusão a Rousseau pode parecer uma ousadia, mas, para quem conhece Morin, sua vida e engajamento político, respeitado por todos os segmentos significativos na França, onde vive, assim como suas teorias e argumentações apaixonadas, isso é plenamente possível.

Dois séculos após a Revolução Francesa, a publicação do livro encontrou muita resistência nas jornadas temáticas organizadas pelo autor à frente de um Conselho destinado a refletir cientificamente sobre a reforma dos saberes nos ginásios franceses. Dessas elaborações teóricas, postas em ação pelo autor, é que resultou a obra $A$ cabeça bem-feita, dedicada à educação e ao ensino a um só tempo, em um produto instigante e motivador.

Partindo da análise dos principais problemas das sociedades contemporâneas e dos propósitos do ensino, Morin propõe a reforma do pensamento e das instituições com base em mudanças no sistema educacional, assumindo toda a complexidade dessa proposta no paradoxo inicial e subtítulo do livro citado: Repensar a reforma, reformar o pensamento.

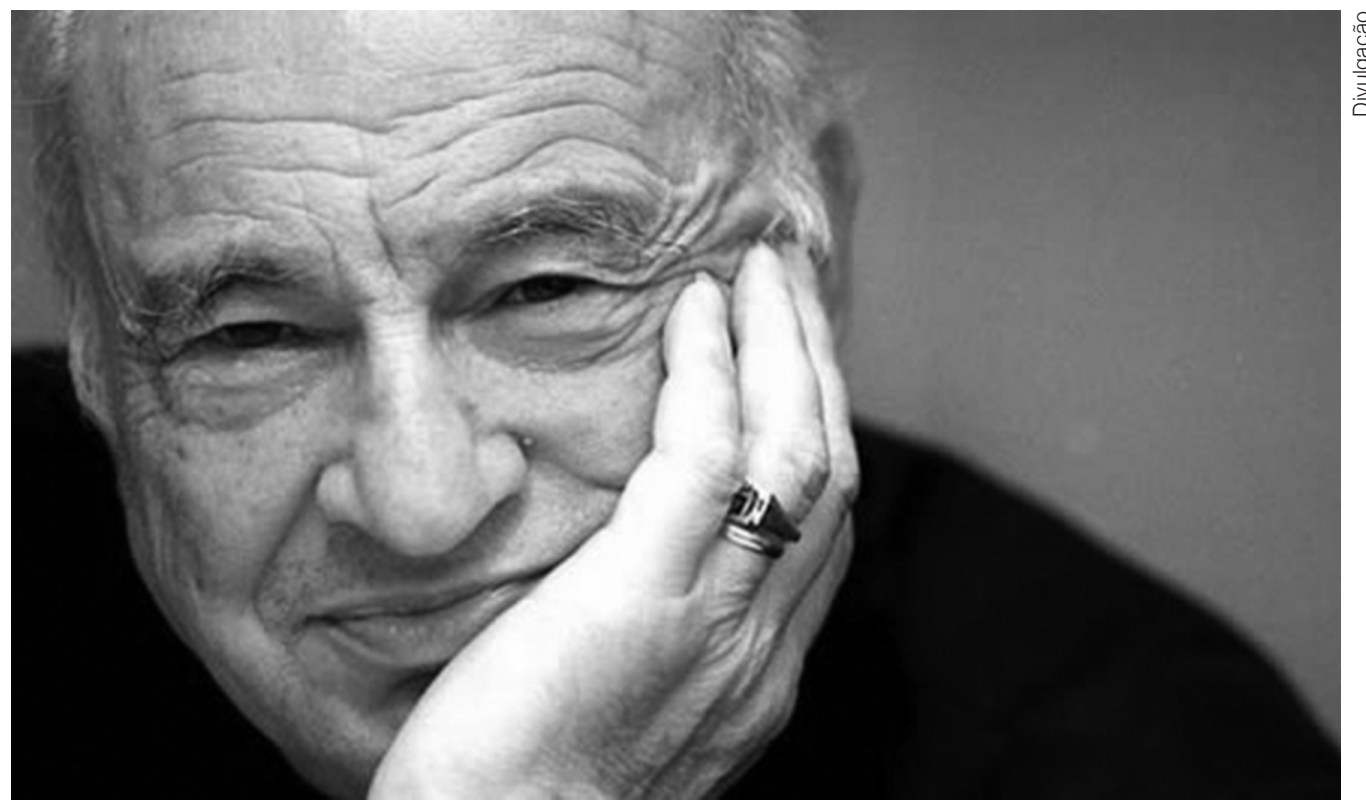

Edgar Morin

2. MORIN, Edgar. A cabeça bem-feita: repensar a reforma, reformar o pensamento. Rio de Janeiro: Bertrand Brasil, 2010.

3. Ibid., p. 11.
Em A cabeça bem-feita, o autor apresenta o conceito de "ensino educativo", que tem por missão "transmitir não o mero saber, mas uma cultura que permita compreender nossa condição e nos ajude a viver, e que favoreça, ao mesmo tempo, um modo de pensar aberto e livre"'. Impossível não notar a proximidade de tal proposta com a essência freiriana da Educação para a Liberdade. Morin, assim como Paulo Freire em toda sua obra, encontra-se em luta para proporcionar aos educandos o aprimoramento das capacidades intelectuais para a autonomia do pensamento e a desenvoltura para lidar com a complexidade 
da vida, especialmente no âmbito do mundo político. A cabeça bem-feita remete, segundo o autor, à primeira finalidade do ensino, formulada por Montaigne na década de 1580: mais vale uma cabeça bem-feita que bem cheia. Em contrapartida, as sociedades contemporâneas vêm se especializando em encher as cabeças com enxurradas de informações acumuladas e empilhadas, e, ao mesmo tempo, carentes de princípios de seleção e organização que lhes deem sentido. O modelo de educação reduzido à instrução, centrado na transmissão de conteúdos fragmentados e descontextualizados, e que entende o conhecimento como acúmulo de informações, não dá conta da complexidade inerente a este século.

Aprender a viver é uma condição que também deve ser objeto da educação. Para isso, é primordial que entendamos a diferença entre informação, conhecimento e sabedoria. A informação está disponível abundantemente, porém, por melhor que seja nosso banco de dados, não há garantias de que ela venha a se converter em conhecimento. Transformar informação em conhecimento pertinente é tarefa do pensamento, através de uma ação que exige dedicação por parte do sujeito - reflexão não estimulada pela cultura do fast. As informações se convertem em conhecimento mediante ações que estimulem os estudantes a pensá-las, conectá-las e contextualizá-las, encontrando pontos de aproximação e distanciamento para articular a diversidade dos dados. Conhecimento é, nesse sentido, informação tratada, significada por operações de pensamento. Esse processo deve se tornar uma prática sistemática e permanente, pois é ele que sustentará a abordagem de problemas complexos.

Morin evoca a sabedoria dos céticos - e com eles a arte de formular as questões filosóficas -, aplicada ao papel social da escola, a partir da citação do poeta Antonio Machado (sob o pseudônimo de Juan de Mairena): "A finalidade de nossa escola é ensinar a repensar o pensamento, a 'des-saber' o sabido e a duvidar de sua própria dúvida; esta é a única maneira de começar a acreditar em alguma coisa" ${ }^{\text {. }}$ O principal problema enfrentado pelo conceito de ensino educativo apresentado em A cabeça bem-feita é estrutural das sociedades ocidentais, remetendo a duas culturas historicamente contrapostas: a científica e a humanista. A origem dessa contraposição entre razão e emoção, cultura e natureza, pode ser encontrada na separação platônica entre o mundo do sensível e do inteligível. A retomada de Heráclito por Nietzsche trouxe ao pensamento contemporâneo uma nova perspectiva, em que a mudança volta a ser uma novidade na Teoria do Conhecimento. Platão, ao separar o mundo em mundo sensivel (doxa) e mundo inteligível (episteme), resolve o paradoxo epistemológico da história da filosofia entre os pensadores pré-socráticos Heráclito e Parmênides - já que imagina a questão da mudança em Heráclito como referente ao mundo sensível, onde tudo é conhecido e mensurado pelos sentidos, podendo, portanto, corromper-se; enquanto para Parmênides, conhecer referia-se à essência de todas as coisas, que permanece idêntica em si mesma. Dessa forma, quando Heráclito refere-se ao ser humano, estaria mencionando a diversidade de cores, gêneros, tamanhos, pesos e outros, enquanto Parmênides estaria mencionando as verdades constantes, definindo a razão como essência imutável do homem. 
comunicação \& educação • Ano XVII • número 1 • jan/jun 2012

Heráclito, revisitado pelo pensamento contemporâneo, aponta para um movimento de reencantamento do mundo, pautado na necessidade, também destacada por Morin, de restituir ao mundo sua complexidade artificialmente perdida. "Um saber só é pertinente se é capaz de se situar num contexto".

Essa dicotomia é levada ao extremo, segundo ele, pelas superespecializações e pelo confinamento e despedaçamento do saber. Devido à própria complexidade do desenvolvimento e da acumulação dos saberes, o autor reconhece as vantagens da divisão das ciências e de seus desenvolvimentos disciplinares, apontando que o papel da escola deveria ser também o de corrigir possíveis aberrações. Contudo, o ensino continua reduzido ao simples, separando o que está ligado, decompondo e não recompondo, eliminando desordens e contradições:

Esse pensamento que recorta, isola, permite que especialistas e experts tenham ótimo desempenho em seus compartimentos, e cooperem eficazmente nos setores não complexos de conhecimento, notadamente os que concernem ao funcionamento das máquinas artificiais; mas a lógica a que eles obedecem estende à sociedade e às relações humanas os constrangimentos e os mecanismos inumanos da máquina artificial e sua visão determinista, mecanicista, quantitativa, formalista; e ignora, oculta ou dilui tudo que é subjetivo, afetivo, livre, criador $^{6}$.

Ainda de acordo com Morin, vivemos em um mundo que corre o risco da hiperespecialização do investigador. Nesse contexto, os conceitos e as linhagens das disciplinas podem servir também para seu isolamento - e, para que isso não ocorra, é necessário que haja uma abertura ao conhecimento global. Ele defende que a ciência seja multifocalizada e polidimensional, por meio do trabalho paralelo às abordagens e aos entendimentos de outras áreas, a fim de tornar possível a cooperação, a policompetência e a troca. Além disso, é ressaltada a autonomia do indivíduo em relação ao ambiente biológico e sociocultural, porém em caráter relacional e relativo.

Morin reconhece a falta de uma concepção ampla do sujeito na sociedade, já que a realidade complexa, de diversas alusões à multiplicidade e à transdisciplinaridade, evoca novas formas de ensino e aprendizado. Ele propõe uma reforma no pensamento e no sistema de ensino, não apenas na trama pedagógica, mas em relação às experiências vivenciadas como produção do conhecimento. $\mathrm{O}$ ensino atual precisa ensinar a viver, muito mais do que servir para transmitir conteúdos.

Este ensinar a viver, baseado na condição humana, deve ser interiorizado profundamente no sujeito, orientando-o de forma permanente, capacitando-o a se auto-organizar e a se perceber como parte da teia da vida. Dessa forma, o ensino tem de promover a formação integral do indivíduo, preparando os estudantes para o enfrentamento do imprevisto e das mudanças; mostrando que o conhecimento traz em si a possibilidade da ilusão e do erro; ajudando o sujeito a compreender problemas fundamentais do nosso mundo enquanto 
da solidariedade e o respeito à diversidade e à multiplicidade; e favorecendo a inclusão e a troca de experiências.

O conhecimento precisa ser compreendido como manifestação da cultura de um povo, de uma época, de uma sociedade. Morin propõe um diálogo entre o velho e o novo, especialmente a partir de séries, filmes e obras literárias, a fim de ver o diferente e aprender, com este, a conviver.

\section{O PENSAMENTO COMPLEXO}

Na busca por um novo modelo para a Educação, Morin trata, em todos os seus livros, da questão da complexidade ou do pensamento complexo. Porém, foi com o advento da cibernética e da teoria da informação que o tema tornou-se objeto de estudo do autor, reunindo o empírico, o lógico e o racional. Nesse emaranhado de conhecimento, quando algo não está claro e quando não é possível ordenar facilmente as ideias concebidas, a palavra complexidade é comumente utilizada.

O vocábulo complexo (originário do latim complexus) significa aquilo que é tecido em conjunto, o que torna possível visualizar a imagem que ilustra sua semântica. "É complexo o que não pode se resumir a uma lei, nem a uma ideia simples [...]. A complexidade é uma palavra-problema e não uma palavra-solução."”

Para demonstrar a realidade é indispensável não negligenciar os diversos aspectos que constituem uma visão reducionista. $\mathrm{O}$ pensamento complexo surge quando o modo simplificador de pensar falha - não implicando, porém, a eliminação de tal formato de pensamento:

O pensamento disjuntivo isola o que separa e oculta tudo o que religa, interage, interfere. Nesse sentido, o pensamento complexo aspira ao conhecimento multidimensional. Mas ele sabe, desde o começo, que o conhecimento completo é impossível: um dos axiomas da complexidade é a impossibilidade de uma onisciência ${ }^{8}$.

É necessário distinguir, mas não isolar. No momento em que se organiza o conhecimento, é feita pelo sujeito a seleção de dados significativos e a rejeição de dados não significativos. Essa operação que se utiliza da lógica é, de fato, comandada por princípios e paradigmas empíricos ocultos que guiam nossas escolhas sem que tenhamos consciência disso.

$\mathrm{Na}$ tentativa de captar a essência da complexidade proposta, o pensador francês compara suas reflexões acerca do pensamento complexo a uma tapeçaria:

Imaginemos uma tapeçaria contemporânea. Ela comporta fios de linho, seda, algodão, lã, de cores variadas. Para conhecê-la, seria interessante conhecer as leis e princípios relativos a cada uma dessas espécies de fio. Contudo, a soma dos conhecimentos sobre cada tipo de fio que compõe a tapeçaria é insuficiente para conhecer essa nova realidade que é o tecido, isto é, as qualidades e propriedades próprias desta textura, como, além disso, é incapaz de nos ajudar a conhecer sua forma e sua configuração ${ }^{9}$.

Com esse modelo, Morin sugere três etapas complementares de complexidade: a primeira mostra que conhecimentos simples não ajudam a conhecer 
comunicação \& educação • Ano XVII • número 1 • jan/jun 2012

as propriedades do conjunto, ou seja, a tapeçaria é mais do que a soma dos fios que a constituem. A segunda revela que o fato de existir uma tapeçaria faz com que as qualidades dos fios não possam ser expressas na totalidade, já que estão inibidas ou virtualizadas. Assim, o todo é menor que a soma de suas partes. A terceira etapa sugere que o todo é, ao mesmo tempo, maior e menor que a soma de suas partes.

A noção de totalidade do saber é, para os alunos, como uma mola propulsora, estimulando-os a estudar por uma causa maior - pois o saber adquirido nas escolas, muitas vezes questionado em relação à sua aplicabilidade, somente passa a ter sentido quando compreendido no contexto geral, no complexo da realidade. A falta de compreensão do todo tira a possibilidade de reflexão e discussão, criando uma espécie de alienação do conhecimento.

A proposta de Morin para o paradigma da disjunção é sua substituição pela distinção, que permite distinguir sem separar, apropriando-se de técnicas dialógicas e sistêmicas para uma análise complexa. Esse curso de pensamento resultará no conjunto de novas concepções, visões, descobertas e reflexões.

Nesse sentido, pode-se imaginar, de forma mais imediatista, que a ação simplifica - porém Morin ressalta que a ação é uma decisão, uma escolha e também um desafio. A noção do desafio inclui a consciência do risco e das incertezas, ou seja, em seu desenvolvimento a ação escapa às intenções primeiras, percorrendo um universo de interações com o meio ambiente, podendo inclusive se tornar contrária ao pensamento inicial. Dessa forma devemos, de acordo com o juízo complexo, seguir a ação e corrigi-la caso ainda tenhamos tempo.

A condição do homem no planeta está sempre presente no pensamento universal, que busca entender como se constrói a consciência da espécie humana. Em um tempo marcado pela racionalização e pela lógica cartesiana, o autor se propõe a ir à busca de um sujeito responsável, ético, solidário e, ao mesmo tempo, poético - um sujeito autônomo cujo conhecimento "progride não tanto pela sofisticação, formalização e abstração, mas principalmente pela capacidade de contextualizar e englobar" ${ }^{\prime 10}$. Assim, o ser humano reencontra-se na união das suas dimensões naturais (biológica, física, viva) e supranaturais (pensamento, cultura e consciência).

Morin entende a razão, a consciência, o homem, o planeta e o cosmos como sistemas vivos que alimentam e realimentam a condição do pensamento em uma tetralogia: ordem, desordem, interação e reorganização. Trata da incerteza como condição natural do pensamento e da produção humana. Fator gerador do avanço das ciências e do entendimento da espécie e do planeta, a incerteza presente em tudo que foi criado pelo homem enfatiza a necessidade de consciência e de compreensão da nossa condição de seres humanos, bem como da consciência ética e da sociedade.

No seu pensamento integrado, ele não separa o ser humano, que denomina sujeito responsável de suas atitudes em relação a si mesmo, do mundo e das coisas. Por isso, também a ética faz parte do ser e do agir na sociedade. Nesse 
“[...] a ética não se impõe imperativamente nem universalmente aos cidadãos; cada um terá de escolher por si mesmo os seus valores e ideais, isto é, praticar a autoética"11.

De acordo com esse pensamento, esta Ética se reveste de compaixão, ternura e solidariedade, reflexos de um sujeito livre e responsável. A Ética, para Morin, é fundamentalmente reconstrutora do pensamento, amparando a consciência individual e coletiva do sujeito, "[...] o que exige uma educação voltada para o autoconhecimento (aprender a ser), para a convivência (aprender a conviver), para a construção do conhecimento (aprender a aprender) e para a tomada de decisões (aprender a comprometer-se)"12.

\section{OS NOVOS DESAFIOS PARA OS EDUCADORES}

A partir dessas perspectivas, acrescentam-se ao trabalho dos educadores os desafios das tecnologias de comunicação. Contudo, como entender esse fenômeno? Formada a partir dos radicais gregos tekhno (de tékhné ou arte, artesanato, indústria, ciência) e de logía (de logos ou linguagem), a palavra tecnologia guarda em seu berço etimológico um significado indubitável e, consequentemente, abrangente. Ao ser apontado como tratado ou dissertação sobre uma arte, exposição das regras de uma arte, o debatido léxico revela-se norteador de rumos sob os quais transitam as mais diversificadas habilidades.

O citado vocábulo detém uma falsa aura de atualidade, embora o conceito que expresse permeie a história humana desde seus primórdios. Chama atenção o fato de que os suportes descritos pela raiz grega tornaram-se obsoletos após o advento de outra tecnologia: o papel. Entretanto, vale salientar que foram precisos alguns milhares de anos para que cada avanço fosse superado por outro. Na atualidade, porém, tal superação é quase imediata. O que, há alguns minutos, era novo e ousado, torna-se agora velho, ultrapassado e obsoleto com uma rapidez inimaginável.

Os questionamentos de Edgar Morin, presentes no livro Educar na era planetária: o pensamento complexo como método de aprendizagem no erro e na incerteza humana, mostra de forma categórica a diferencial equalização de rumos vividos pela tecnologia e pela sociedade, com ênfase na educação. Logo na apresentação da obra, feita por Jorge Werthein, então representante da Unesco no Brasil, há o alerta sobre a preocupante falta de linearidade imposta pelo avanço tecnológico: "O notável avanço da ciência e da tecnologia não foi nem está sendo seguido de avanços no plano existencial e ético. As guerras continuam e a violência se alastra e se instaura em ambientes que, há alguns anos, não poderíamos imaginar"13.

Vale aqui uma reflexão sobre o fato de as tecnologias do passado - a pintura rupestre, a escrita cuneiforme ou hieroglífica e o papel - terem sido usadas, durante milhares de anos, como meios que permitiram acesso ao conhecimento, sempre quando uma gama de determinações herméticas e excludentes, reguladas por normatizações e diretrizes preestabelecidas, fosse plenamente atendida. Assim, e também a partir das considerações tecidas por
11. Ibid., p. 67

12. Os conceitos apresentados fazem parte da Carta de Fortaleza, elaborada em decorrência da Conferência Internacional realizada pela Unesco de 21 a 24 de setembro de 2010, em Fortaleza, Ceará - com o intuito de comemorar os 10 anos de lançamento da obra Os sete saberes para uma educação do futuro, escrita por Edgar Morin, e verificar as principais razões pelas quais este precioso documento, apesar de publicado em várias línguas e de sua relevância reconhecida mundialmente, vem sendo pouco trabalhado nas escolas e em outros espaços educativos, tanto no Brasil como em outros países.

13. Ibid., p. 7. 
comunicação \& educação • Ano XVII • número 1 • jan/jun 2012

Morin, é viável considerar que as tecnologias do presente tendem também a caminhar para a mesma finalidade, apesar da etérea névoa de novidade que paira sobre elas. Para que novos rumos sejam trilhados, Morin sugere três pontos fundamentais para a reforma dos modos de conhecimento, de pensamento e de ensino, visualizando uma efetiva educação na era planetária.

O primeiro deve considerar problemas de método. Frequentemente esse termo é confundido com metodologia, o que enrijece seu caráter programador; método, aqui, é entendido como uma disciplina do pensamento, algo que deve ajudar as pessoas a elaborar sua estratégia cognitiva, situando e contextualizando as informações, conhecimentos e decisões e tornando-os aptos a enfrentar o desafio onipresente da complexidade (trata-se de um "método de aprendizagem na errância e na incerteza humanas").

É relevante, ainda, conferir sentido à noção de complexidade. Trata-se de um termo cada vez mais utilizado, mas o que ele exprime não é uma elucidação, e sim uma incapacidade de descrever o mundo, uma confusão da mente. Para evitar explicações aprofundadas, afirma-se que o objeto "é complexo". Torna-se necessário, dessa forma, proceder a uma verdadeira reviravolta, mostrando a complexidade como um desafio que a mente deve e pode ultrapassar, apelando a princípios que permitam o exercício do pensamento complexo.

Por último, deve-se esclarecer a própria noção de era planetária em sua perspectiva histórica e em sua complexidade multidimensional - indicando, além disso, que, mesmo diante da crise generalizada do século que ora se inicia, configura-se a emergência de uma infraestrutura de sociedade-mundo que não chegou ainda a nascer.

Partindo da ideia básica de que o conhecimento deve trabalhar na incerteza e na dificuldade, com a intenção de chegar às chamadas Novas racionalidades, para permitir uma caminhada aos novos tempos, quando a unicidade do saber deve dar lugar à pluralidade dos saberes em diálogo, e a fragmentação à unidade, temos que, como numa espécie de viagem, transitar pelo saber, atravessando as disciplinas para compor o todo capaz de ser utilizado por indivíduos em sua relação com o mundo global ${ }^{14}$.

Finalizando, queremos enfatizar que, neste trabalho, pudemos contar com a participação de profissionais das mais diversas áreas do conhecimento para, juntos, refletirmos sobre a teoria do Professor Edgar Morin e sua aplicabilidade à Educação de hoje e de amanhã - tempo em que as tecnologias digitais representam novos desafios para todos os educadores, tornando fundamental a necessidade de conhecê-las para incorporá-las ao nosso trabalho pedagógico.

14. CURY, Lucilene. A nova racionalidade sob um olhar amoroso. In: MEDINA, Cremilda; GREGO, Milton (org.). Caminhos do saber plural. São Paulo: ECA/USP, 1999.

\section{REFERÊNCIAS BIBLIOGRÁFICAS}

CARVALHO, Edgar de Assis (org.) Ética, solidariedade e complexidade. São Paulo: Palas Athena, 2000.

(org.). Coleção Grandes Educadores - Edgar Morin. Produção: 2006, Brasil, duração 40 min. Distribuição: Artesanato Digital Cine Clube. 
CURY, Lucilene. A nova racionalidade sob um olhar amoroso. In: MEDINA, Cremilda; GREGO, Milton (org.). Caminhos do saber plural. São Paulo: ECA/ USP, 1999.

MORIN, Edgar. Os sete saberes necessários à educação do futuro. Brasília: Unesco, 2003.

Introdução ao pensamento complexo. Porto Alegre: Editora Sulina, 2005.

Educação e complexidade: os sete saberes e outros ensaios. 5. ed. São Paulo: Cortez, 2009.

A cabeça bem-feita: repensar a reforma, reformar o pensamento. Rio de Janeiro: Bertrand Brasil, 2010.

MORIN, Edgar; CIURANA, Emilio-Roger; MOTTA RAÚL, Domingo. Educar na era planetária: o pensamento complexo como método de aprendizagem no erro e na incerteza humana. São Paulo: Cortez, 2003.

\section{Endereços eletrônicos}

CARTA DE FORTALEZA. Disponível em: <http://www.robertocrema.net/index. php?option=com_content $\&$ view=article $\&$ id $=138$ : carta-de-fortaleza\&catid=57:doc umentos\&Itemid=54>. Acesso em: 21 out. 2011. 


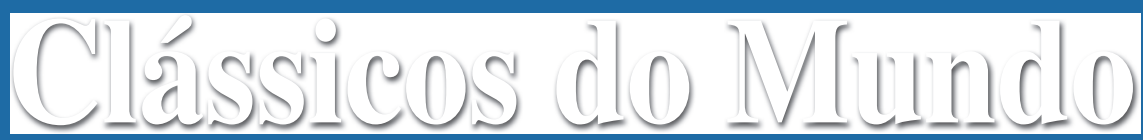

\section{Viagem de saber com bom sabor pela literatura de todos os tempos}

Conhecer as obras clássicas da literatura é fundamental para o desenvolvimento do imaginário e da formação cultural, pois consolidam, no melhor feitio poético, valores e grandezas da história da civilização a favor de um mundo mais irmão e solidário.

\section{Série juvenil}

Em uma instigante viagem de conhecimento e prazer, série promove um encontro inaugural do jovem leitor com algumas das mais importantes obras literárias de diversos povos e países do planeta, narradas em boa prosa contemporânea.

As aventuras de El Cid Campeador Manuscrito de Per Abbat contado por José Arrabal ilustrado por Daniel Araujo Cód. 513717 176 págs. ISBN: 9788535622409

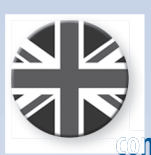

Romeu e Julieta William Shakespeare ntado por José Arrabal ilustrado por Daniel Araujo cód.: 514012 280 págs. ISBN: 9788535622850
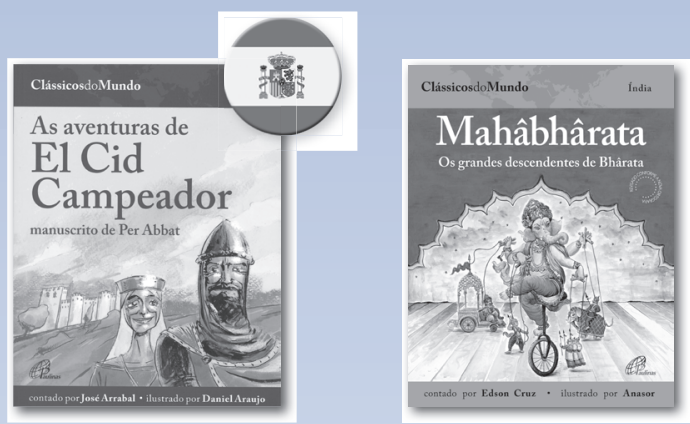

Mahâbhârata

Os grandes descendentes de Bhârata contado por Edson Cruz ilustrado por Anasor

Cód. 517283

168 págs.

ISBN: 9788535626513
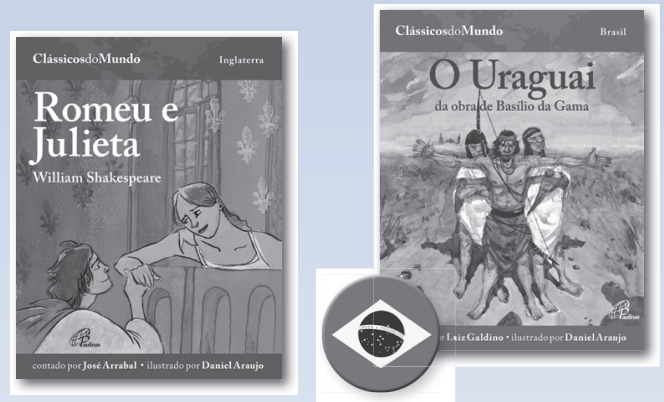

0 Uraguai - da obra de Basílio da Gama contado por Luiz Galdino ilustrado por Daniel Araujo Cód. 519154

152 págs.

ISBN: 9788535628159

\section{Série infantil}

Em prosa atual, apresenta grandes romances, novelas, contos tradicionais e mitológicos consagrados, comunicando as tramas presentes em suas matrizes literárias com expressiva originalidade e precisa beleza, para o prazer da leitura.

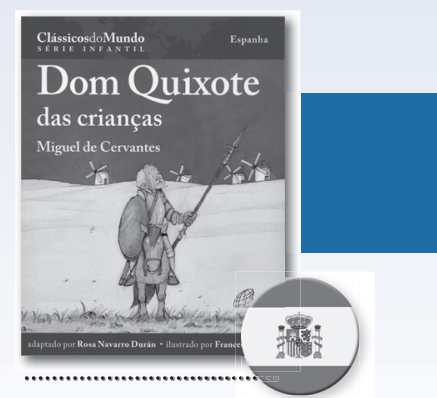

Dom Quixote das crianças Miguel de Cervantes adaptado por Rosa Navarro Durán adaptado para o português por José Arrabal ilustrado por Francesc Rovira Cód. 513571 248 págs. ISBN: 9788535622249
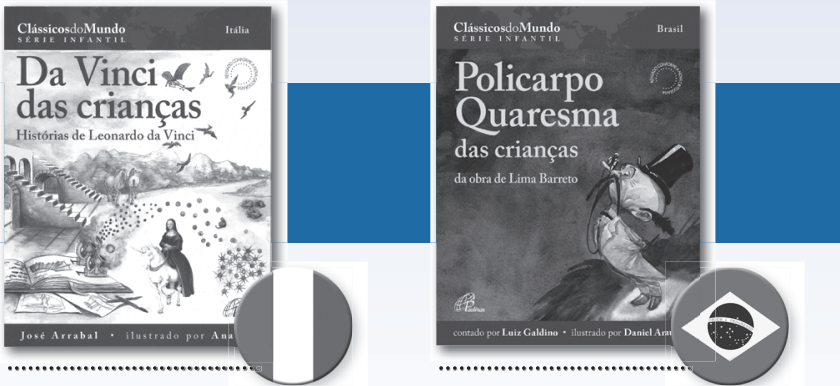

Policarpo Quaresma das crianças Da obra de Lima Barreto adaptado por Luiz Galdino ilustrado por Daniel Araujo Cód. 517313 262 págs.

ISBN: 9788535626551

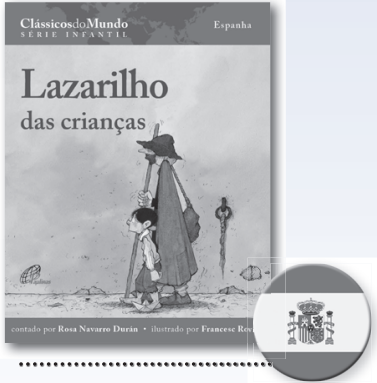

Lazarilho das crianças contado por Rosa Navarro Durán

Em livre recriação para o português por Luiz Galdino ilustrado por Francesc Rovira Cód. 520020 228 págs.

ISBN: 9788535629330

\section{À venda na Rede Paulinas de Livrarias Se preferir, ligue 08007010081 ou acesse www.paulinas.org.br}

